See Article page XXX

\section{Commentary: Assessing recovery of ejection fraction after mitral repair: One year after operation, are we there yet?}

\author{
Donald Glower, MD
}

Hibino and colleagues ${ }^{1}$ present the results of a randomized trial of leaflet resection versus leaflet preservation in 104 patients undergoing mitral repair for posterior prolapse. The authors conclude that the mitral repair technique used did not influence postoperative left ventricular (LV) reverse remodeling, and that although $\mathrm{LV}$ end diastolic dimensions recovered before discharge, improvements in LV end systolic dimension were evident 12 months after repair.

Changes in LV volumes after mitral valve repair have been well documented. The value of this study is to confirm prior reports of changes in LV volumes after mitral repair, using data from the second reported randomized trial of resect versus respect techniques. These data are an update of the initial trial report. ${ }^{2}$ Other studies have compared the resect versus respect repair techniques, but there has been only 1 other randomized trial. ${ }^{3}$ In terms of new data comparing LV volumes after resect versus respect repairs, this is a negative study with no differences seen.

This trial does have minor limitations. The results are reported as intention to treat, whereas most prior studies have been reported with as-treated results, which might be more useful in retrospective prediction of outcomes. Secondly, this series examined a select group of patients with posterior mitral prolapse and ejection fraction $>40 \%$. This would include most prolapse patients undergoing repair. Whether

From the Department of Surgery, Duke University, Durham, NC.

Disclosures: The author reported no conflicts of interest.

The Journal policy requires editors and reviewers to disclose conflicts of interest and to decline handling or reviewing manuscripts for which they may have a conflict of interest. The editors and reviewers of this article have no conflicts of interest.

Received for publication Sept 12, 2021; revisions received Sept 12, 2021; accepted for publication Sept 13, 2021.

Address for reprints: Donald Glower, MD, Department of Surgery, Duke University, Duke University Medical Center, Box 3851, Durham, NC 27710 (E-mail: glowe001@mc.duke.edu)

J Thorac Cardiovasc Surg 202 $: 1-2$

$0022-5223 / \$ 36.00$

Copyright (c) 2021 by The American Association for Thoracic Surgery

https://doi.org/10.1016/j.jtcvs.2021.09.019

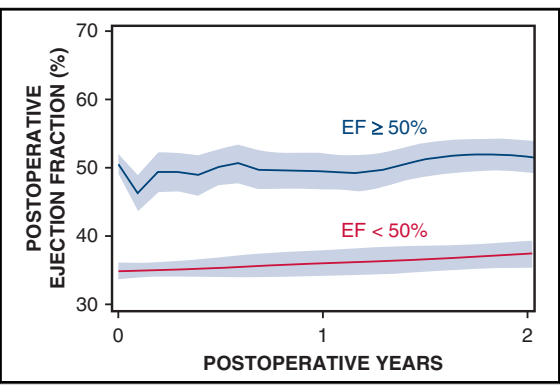

Recovery of ejection fraction (EF) after mitra repair as a function of preoperative $\mathrm{EF}(95 \%$ confidence interval is shaded).

\section{CENTRAL MESSAGE \\ Assessment of recovery of ejec- tion fraction after mitral repair requires about 1 year.}

or not these results apply to patients with other valve etiologies or more significant LV dysfunction is less clear. On the positive side, this prospective, randomized trial made use of very high quality echocardiography follow-up using a core laboratory. The degree of echocardiography followup is higher than in most retrospective series.

This study did not examine time intervals between 30 days and 1 year or over 1 year in terms of recovery of ejection fraction. Figure 1 shows data from a series of 1069 patients undergoing mitral repair for mitral regurgitation at Duke University. These patients were followed with clinical echocardiography over 2 years after surgery. Figure 1 suggests that indeed 30 days is too early to obtain stabilization of ejection fraction in patients with baseline ejection fraction of $50 \%$ or greater. Patients with baseline ejection fraction $<50 \%$ have a much more prolonged

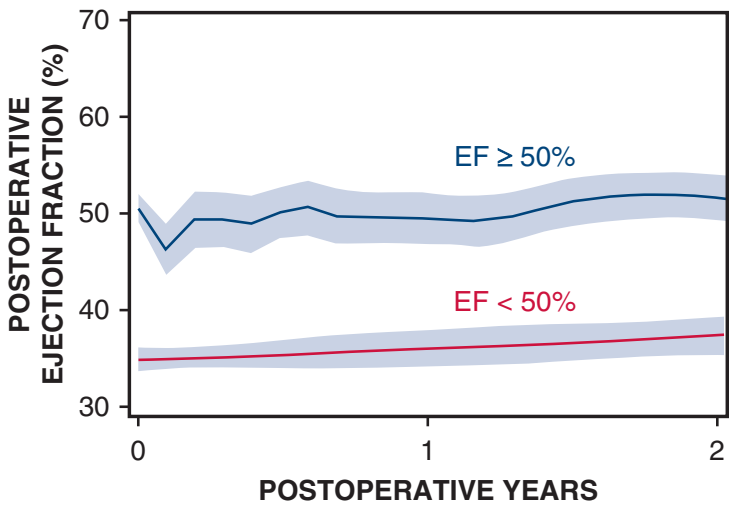

FIGURE 1. Recovery of ejection fraction (EF) after mitral repair as a function of preoperative EF ( $95 \%$ confidence interval is shaded). 
recovery of ejection fraction that may require more than 2 years, if recovery occurs at all.

The value of the study conducted by Hibino and colleagues ${ }^{1}$ is in its high-quality, prospective echocardiographic data showing that one needs to wait about 1 year and not 30 days to judge the effectiveness of the timing of mitral repair to prevent permanent or long-lasting LV dysfunction. Current guidelines recommend ejection fraction of $60 \%$ or end systolic diameter of $4.0 \mathrm{~cm}$ as red lines to indicate repair. These guidelines are designed to give at least $75 \%$ of patients a normal ejection fraction of $50 \%$ at 1 to 12 months after repair. These guidelines are based on data looking at recovery of ejection fraction at 1 to 12 months as a measure of successful timing of repair. ${ }^{4}$ The data offered by Hibino and colleagues ${ }^{1}$ support using ejection fraction at 1 year as a measure of appropriate timing of mitral repair. Good things take time. To assess recovery of LV function after mitral repair, at 1 year we can say: "We are there."

\section{References}

1. Hibino M, Dhingra NK, Verma S, Chan V, Quan A, Gregory AJ, et al. Mitral repair with leaflet preservation vs. leaflet resection and ventricular reverse remodeling from a randomized trial. J Thorac Cardiovasc Surg. 2021;XX:XX-XXX.

2. Chan V, Mazer CD, Ali FM, Quan A, Ruel M, de Varennes BE, et al. Randomized, controlled trial comparing mitral valve repair with leaflet resection versus leaflet preservation on functional mitral stenosis: the CAMRA CardioLink-2 Study. Circulation. 2020;142:1342-50.

3. Falk V, Seeburger J, Czesla M, Borger MA, Willige J, Kuntze T, et al. How does the use of polytetrafluoroethylene neochordae for posterior mitral valve prolapse (loop technique) compare with leaflet resection? A prospective randomized trial. J Thorac Cardiovasc Surg. 2008;136:1200-6.

4. Enriquez-Sarano M, Tajik AJ, Schaff HV, Orszulak TA, McGoon MD, Bailey KR, et al. Echocardiographic prediction of left ventricular function after correction of mitral regurgitation: results and clinical implications. J Am Coll Cardiol. 1994;24: $1536-43$. 